\title{
Gestión y vida económica en las Cofradías y Hermandades del Antiguo Régimen: un ejemplo andaluz
}

\author{
Management and economic life in religious confraternities during \\ the Ancient Regimen: an andalusian case \\ Manuel SANTOS GÓMEZ \\ Universidad de Córdoba, \\ 142sagom@uco.es
}

\begin{abstract}
Resumen: En las siguientes líneas se aborda la gestión y vida económica de las cofradías del Antiguo Régimen a partir de un ejemplo concreto a nivel andaluz, una muestra representativa de las hermandades de la ciudad de Córdoba, especialmente las radicadas en la parroquia de San Andrés Apóstol. Para ello se profundizará en los ingresos y los gastos de estas corporaciones, dándonos numerosos detalles de su vida y finalidades, para concluir con la existencia de una gestión económica que buscase la mayor rentabilidad para cada una de estas instituciones.
\end{abstract}

Abstract: In next lines it will be broached the management and economic life in religious confraternities during Ancient Regimen from an andalusian case: a representative sample of confraternities in the town of Cordoba, especially ones which were radicated in the parish of San Andres Apostol. For that, it will be deepened in entries and spending of these corporations, offering many details of its life and purposes, concluding demonstrating the existence of an economic management that pursued the highest profitability for each one of these institutions.

Palabras clave: Cofradía, Asociacionismo religioso, instituciones eclesiásticas, vida económica, gestión económica, vida urbana, Córdoba, Edad Moderna, Antiguo Régimen.

Keywords: Confraternity, Religious associations, ecclesiastic institutions, economic life, economic management, urban life, Cordoba, Modern Age, Ancient Regimen. 
Sumario:

I. Introducción.

II. Ingresos.

III. Gastos.

IV. Conclusión: una gestión económica.

V. Anexo.

Recibido: septiembre 2020.

Aceptado: noviembre 2020. 


\section{INTRODUCCIÓN}

El fenómeno del asociacionismo religioso, conformado por instituciones como cofradías, hermandades, congregaciones y órdenes terceras, entre otras, tuvo un enorme desarrollo durante los siglos de la Modernidad. Desde el siglo XVI asistimos a la eclosión de corporaciones en el mundo católico, una realidad que arraigó de manera excepcional en el Mediodía peninsular. Así, los reinos andaluces constituyen un espacio privilegiado para el estudio de este fenómeno tan complejo pero indispensable para estudiar el ámbito urbano durante el Antiguo Régimen.

Como cualquier corporación eclesiástica de estos tiempos, las hermandades y cofradías pueden considerarse instituciones sociales y de poder. En este sentido, sobre las mismas se puede aplicar el análisis propio que se puede deducir a partir del estudio de las élites del italiano Albertoni ${ }^{1}$ y que más adelante Gómez Navarro aplicara a la Iglesia del Antiguo Régimen ${ }^{2}$, y que caracteriza a cualquier institución social y de poder por reunir una localización, y por ende un espacio, una organización interna, unas rentas y sistema económico, unos agentes sociales y unas funciones o finalidades concretas. Este método de análisis, en el que ya hemos podido profundizar en trabajos anteriores ${ }^{3}$, nos ofrece grandes posibilidades en este fenómeno sociorreligioso que florecía en las ciudades y villas hispánicas y cuyo estudio desde el punto de vista social ofrece nuevas e interesantes perspectivas, sobre todo por ser un fenómeno que atravesaba todos los estratos de la sociedad, conformando un auténtico caleidoscopio. Por ello, si bien cada aspecto anteriormente señalado permite una profundización, es importante no olvidar la perspectiva social que amplía las miras y resultados de la investigación histórica.

${ }^{1}$ ALBERTONI, E., "Teoría de las élites y elitismo (apuntes para un análisis histórico y actual)", en Sistema: revista de ciencias sociales, 83 (1988) 43-56.

${ }^{2}$ GÓMEZ NAVARRO, S., "Cenobios femeninos de la España barroca: una mirada desde la Historia Social y del Género", en REVENGA DOMÍNGUEZ, P. (coord.), Arte barroco y vida cotidiana en el mundo hispánico. Entre lo sacro y lo profano, Córdoba 2017, pp. 279-280.

${ }^{3}$ Una síntesis de los mismos en SANTOS GÓMEZ, M., "Una aproximación al asociacionismo religioso: la ciudad de Córdoba en el Antiguo Régimen", en MARINAS ARMEDÍA, A. (coord.), El mérito de la investigación, Córdoba 2019, pp. 38-41. 
En las siguientes líneas buscamos realizar un acercamiento al apartado económico de las cofradías y hermandades del Antiguo Régimen utilizando un ejemplo concreto a nivel andaluz, el caso de la ciudad de Córdoba, un núcleo medio de interior en el que el fenómeno del asociacionismo religioso estaba muy bien representado ${ }^{4}$. Estudiar las rentas y la vida económica de estas corporaciones nos lleva fundamentalmente a los fines de las mismas, y a toda una gestión, más o menos eficaz y ambiciosa que pretendía no solo mantener viva la corporación sino dotarla de una mayor fuerza a través de los signos externos. Para el estudio de esta vida económica combinaremos varios niveles de análisis, un nivel medio a escala local a través de los datos contenidos en los libros de hacienda de eclesiásticos pertenecientes al catastro de Ensenada con otra escala más pequeña centrándonos en las hermandades que conforman una muestra reducida pero representativa, fundamentalmente las cofradías asentadas en la parroquia de San Andrés Apóstol en la centuria del Setecientos ${ }^{5}$, pero no solo, gracias a sus libros conservados en los fondos parroquiales. Facilitaremos la organización de la información, haciendo un repaso por tres puntos esenciales: ingresos, gastos y gestión de los recursos de estas corporaciones.

Las fuentes principales que contienen esta vida económica son las cuentas que eran llevadas por los administradores de la hermandad, generalmente por los hermanos mayores. Así, en un libro especial iban apuntando los ingresos y los gastos para posteriormente poder dar cuenta al obispado. De hecho, de manera periódica era necesario presentar los extractos de los ingresos y gastos de la corporación ante la administración episcopal para que revisara las mismas y las aprobara, previo visto bueno del cabildo de hermanos. La práctica más frecuente era que los hermanos mayores salientes presentaran sus rendimientos poco después de abandonar el cargo, para que quedase aprobado el alcance favorable o desfavorable al mismo y se procediese a saldar las deudas contraídas entre la cofradía y su ex-dirigente, independientemente de quien fuese alcanzado. Normalmente el provisor aprobaba las cuentas presentadas, matizando algunos detalles o dando indicaciones para tener en cuenta de cara al futuro ${ }^{6}$, quedando

${ }^{4}$ De hecho en el informe realizado por el conde de Aranda en 1771 se recogen 123 cofradías en la capital cordobesa, con una ratio de alrededor de 280 habitantes por hermandad, la tercera más baja de entre las grandes ciudades españolas, más aún que la de Sevilla, Madrid, Barcelona o Valencia y solo superada por Toledo y Valladolid. ARIAS DE SAAVEDRA ALÍAS, I., y LÓPEZ-GUADALUPE MUÑOZ, M. L., "Cofradías y ciudad en la España del siglo XVIII", en Studia Historica. Historia Moderna, 19 (1998) 200.

${ }^{5}$ La parroquia de San Andrés Apóstol albergaba cuatro cofradías que representan muy bien la diversidad de hermandades existentes en la ciudad. Las preceptivas sacramental y de ánimas, con gran apoyo del clero parroquial, pero menos devocionales; una gremial en honor a Nuestra Señora de las Nieves y Santo Domingo de Silos, una mariana del rosario, con el título de Nuestra Señora de los Ángeles; y una de una espiritualidad más profunda en honor a San José.

${ }^{6}$ Es interesante ver como ante las nuevas ideas ilustradas del siglo XVIII, que entienden la religiosidad de manera más íntima y menos festiva, los provisores advierten repetidamente 
guardadas copias de dichos apuntes en el archivo del obispado. Este práctica de control eclesiástica permite consultar un gran número de pliegos contables de un importante volumen de cofradías cordobesas del Antiguo Régimen que no solo nos refieren aspectos estrictos como el montante de ingresos (cargo) y gastos (data), sino recibos de libramientos, inventarios, poderes otorgados y otros documentos que nos permiten reconstruir con precisión los avatares económicos de cada corporación, además de darnos muestra de un importante número de detalles que nos hablan del día a día de la actividad económica de la institución.

\section{INGRESOS}

En primer lugar, toda institución necesita unos ingresos, aunque sean mínimos, para poder llevar a cabo los fines para los que ha sido creada. Este es también el caso de las hermandades, que disponían de diferentes fuentes de financiación muy variables en función de su vocación (dar culto a Cristo, la Virgen o los santos) y el cumplimiento de las obligaciones y sufragios por los hermanos difuntos. Desde un punto de vista general gozaban de una situación bastante constreñida, por su gran dependencia de las limosnas de cofrades y devotos $^{7}$. Esta dependencia explicaría lo efímero de la vida de algunas de ellas, además de los diferentes altibajos que experimentaban en su desarrollo temporal. Debilidad que era mucho mayor en aquellas corporaciones que no poseían rentas fijas derivadas de arrendamientos o censos que en aquellas que sí la tenían. Por ejemplo, en las cuentas de la hermandad sacramental de San Andrés de 1752 del volumen total de ingresos un $17 \%$ procedía de las limosnas mientras que un $66 \%$ de las rentas de sus diferentes bienes inmuebles y de capital ${ }^{8}$. Aun así, los cofrades debían contribuir de alguna manera a la corporación, pues de ellos dependía en última instancia garantizar la salud de la economía de la misma. Normalmente las limosnas que cada hermano aportaba anualmente a la cofradía venían reguladas en los estatutos de ellas, pero no siempre esta contribución se ajustaba a un número concreto de reales.

Las limosnas anuales con las que tenían que contribuir los cofrades variaban mucho en función de la hermandad; en las más populares eran de

en las cuentas que no se gaste dinero en colaciones y banquetes tras las estaciones de penitencia de Semana Santa, por ser algo contrario al rigor de los días santos, siguiendo las políticas episcopales de la segunda mitad del Setecientos. Un ejemplo en A(rchivo) G(eneral) (del) O(bispado) (de) C(órdoba), Cofradías, 6568/02. Cofradía del Santísimo Sacramento y Nuestra Señora del Rayo. Cuentas. 1751-1753. Cuentas de 1753.

${ }^{7}$ MORGADO GARCÍA, A., "Cofradías y hermandades en el Cádiz de los siglos XVII y XVIII", en Actas de los VII Encuentros de Historia y Arqueología. Gremios, hermandades y cofradias. Una aproximación científica al asociacionismo profesional y religioso en la Historia de Andalucia, San Fernando 1991, t. I, p. 56.

${ }^{8}$ ANEXO. TABLA I. 
menor cuantía mientras que en las de corte más aristocrático sería de mucho más. Así, mientras en la de Belén del Alcázar Viejo era un ochavo, en la del Rosario de los Huérfanos 2 reales $^{9}$, y en las del barrio de Santiago $3^{10}$; mientras que la nobiliaria cofradía de Jesús Nazareno cobraba unos 10 reales mensuales a sus hermanos ${ }^{11}$. En el caso de San Andrés, las cofradías que tenían estipulada una cuota concreta, esta era de 4 reales en el caso de San José, aunque disminuiría a 3 por la buena gestión económica ${ }^{12}$, y 3 en el caso de la cofradía de las Nieves ${ }^{13}$. La cofradía sacramental tendría una obligación similar, que no podemos precisar porque las cuentas reflejan la suma de todos los pagos que tenía lugar el Jueves Santo. Finalmente, la de Ánimas en un principio no pedía una limosna a los hermanos, sino que estos realizasen voluntariamente demandas por las noches por las calles de la collación con faroles en las manos para pedir dinero a los vecinos para los sufragios a las ánimas del purgatorio. Cuando las mismas comenzaron a descender insertaron la obligatoriedad del pago de 4 reales anuales a los hermanos o bien que se encargaran de algún cepo en el que la suma total de limosnas al final del año fuese de más de 5 reales ${ }^{14}$. Algunas hermandades permitían que los pagos fuesen semanales, como el caso de la cofradía de la Vera-Cruz, que daba la posibilidad de pagos de 2 maravedíes a la semana o 3 reales en la mesa del Jueves Santo previa a su salida procesional ${ }^{15}$. La misma práctica se documenta en las cofradías del Campo de la Verdad, muy posiblemente para facilitar a los hermanos humildes los pagos.

No podemos obviar al hablar de las limosnas de los cofrades la existencia de una parte de la nómina de la cofradía que obviaba los pagos preceptivos a la corporación. Establecer una tasa de morosidad es muy difícil al carecer de datos precisos salvo para algunos casos. Por ejemplo, en la cofradía de San José el índice de morosos osciló entre un 1 y un $20 \%$ en los primeros años de vida de la hermandad. Si bien en 1765, 1 de cada 5 cofrades no abonaba las correspondientes cuotas, se observa una lucha por la cofradía para acabar con esto, y así, para 1775 ya no quedaban hermanos negligentes a abonar la

\footnotetext{
${ }^{9}$ MORENO VALERO, M., "Religiosidad popular en Córdoba en el silgo XVIII. Cofradías del Santo Rosario", en Boletín de la Real Academia de Córdoba, de Ciencias, Bellas Letras y Nobles Artes, 112 (1987) 107.

${ }^{10}$ A.G.O.C. Cofradias. 7498/88. 1842.

${ }^{11}$ RAMÍREZ DE ARELLANO Y GUTIÉRREZZ, T., Paseos por Córdoba o sean apuntes para su historia, León 1976, p. 72.

${ }_{12}$ A(rchivo) P(arroquia) (de) S(an) A(ndrés) A(póstol), Libro de la hermandad de los hermanos del tránsito del Señor San José para los cabildos. 1763-1813. Cabildo del día 20 de enero de 1788. Fol. 27 r.-29 v.

${ }^{13}$ A.G.O.C., Cofradias, 6533/01. 1731-1785. Capítulo 9.

14 A.P.S.A.A., Libro de cabildos de la hermandad de Ánimas. 1700-1853. Cabildo del día 18 de enero de 1756. Fol. 25 r.-26 r.

${ }^{15}$ A.G.O.C., Cofradias, 6537/01, Cuentas de la Santa Vera Cruz del convento de San Pedro el Real. 1615-1719. Cuentas de 1719.
} 
limosna correspondiente ${ }^{16}$. Aunque no podamos concretar para el resto de corporaciones, la realidad es que en el seno de las mismas también se dio esta realidad, contra las que las cofradías desarrollaban opciones prácticas para evitar que supusieran un gran perjuicio, como no dar la totalidad de los sufragios correspondientes a aquellos hermanos difuntos que no se encontrasen al corriente de pagos, o directamente darlos de baja de la cofradía si la situación permanecía en el tiempo.

Junto a las aportaciones de hermanos de carácter obligatorio, otra fuente de ingresos que podemos englobar dentro de las limosnas eran las demandas y los cepos. Las demandas eran limosnas que se pedía a los devotos y al pueblo en general para sufragar el culto y otras actividades y que recibía el nombre de las bandejas en las que se efectuaban en muchos casos. Son muy característicos los capítulos en las constituciones de hermandades sacramentales que versan sobre la petición de limosnas de cera para alumbrar al Santísimo Sacramento en las fiestas o en las procesiones, como en el caso de la cofradía de la collación de San Juan de los Caballeros ${ }^{17}$. Esto también se constata en la cofradía sacramental del barrio del Campo de la Verdad. Sin embargo, las demandas más características eran aquellas que se realizaban en unas bandejas, normalmente de plata, en las que en determinadas fechas señaladas los devotos depositaban sus ofrendas.

Un ejemplo lo tenemos en la demanda de este metal precioso con la que rápidamente se dota la cofradía del Rosario del Campo de la Verdad tras su refundación con un peso de 16 onzas para pedir limosna ${ }^{18}$. Eran características algunas cuestaciones públicas que tenían lugar en fechas navideñas, conocidas como días de coplas, en las que se sacaba la imagen del Niño Jesús a las calles para recabar limosnas y se cantaban villancicos. Asimismo, también eran señaladas las que la cofradía de Nuestra Señora del Amparo realizó el día de la Epifanía de 1750, vistiendo a algunos hermanos de los Magos de Oriente ${ }^{19}$. La competición por las demandas podía llegar a generar conflictos entre algunas hermandades con sede compartida, como el caso que Ramírez de Arellano nos relata sobre la disputa que surgió el Jueves Santo del año 1700 entre las hermandades de los Ángeles y San Pedro Advíncula, y del Socorro y Santo Rosario, ambas radicadas en la ermita del hospital de los Ángeles ${ }^{20}$. Tampoco faltan ejemplos en los pleitos consultados en el Archivo del obispado. Estas

${ }^{16}$ A.P.S.A.A., Libro para las cuentas de la hermandad de la cofradia del Señor San José. 1763-1823. Fol. 1 r.-25 r.

${ }^{17}$ Reglas hermandad del Santísimo Sacramento de la parroquia de San Juan de los Caballeros. 1629. Capítulo XV. Apud. ARANDA DONCEL, J., Cofradias y asistencia social en los barrios de San Juan y Todos los Santos (Trinidad), Córdoba 1990, p. 229.

${ }^{18}$ A.G.O.C., Cofradias, 6568/06. 1753-1766. Cuentas de 1754.

${ }^{19}$ MORENO VALERO, M., o.c., p. 109.

${ }^{20}$ RAMÍREZ DE ARELLANO Y GUTIÉRREZ, T., o.c., p. 215. 
peticiones públicas daban también posibilidad a la picaresca de individuos que decían pedir ofrendas para una hermandad y realmente las utilizaban en su beneficio $^{21}$. De ahí, que la propia Iglesia persiguiera estas conductas indeseables regulando que las demandas solo pudieran realizarse en días de fiesta para la cofradía y con permiso del obispo, tal y como refleja la documentación ${ }^{22}$.

Las cofradías de San Andrés de las que conocemos que practicaron más estas demandas fueron la sacramental y la de ánimas. La primera salía por las calles del barrio los domingos y días de fiesta, mientras que la segunda hacía las rondas nocturnas que ya hemos referido. Mucho más interesantes eran las cuestaciones en el arrabal del Campo de la Verdad, donde además de las formas típicas explicadas anteriormente, se detectan también peticiones de aceite, de granos como trigo y cebada, e incluso de habas, lo que nos refiere el carácter agrario de esta barriada y la extracción socioprofesional de sus hermanos. De igual manera, la cofradía sacramental del mismo barrio realizaba 4 ó 5 demandas anuales para el culto del Santísimo, de la imagen de la Virgen del Rayo, los años que se organizaba procesión para costear la misma y una llamada volatera encargada a los cofrades por el hermano mayor, además de otra para ayudar a sufragar los gastos del jubileo circular los años que hubiere ${ }^{23}$.

Los cepos era otra modalidad de limosna en la que el devoto introducía las monedas en una caja a través de una pequeña rendija por la que no cabía más que el dinero. De manera periódica se vaciaban estos cepillos que podían ser más o menos numerosos. Protagonismo destacado tuvieron en la cofradía de las Ánimas, que disponía alguno en su capilla, aunque la mayor parte los repartidos por diferentes casas de hermanos y comercios de la collación ${ }^{24}$. La relevancia de los cepillos también se percibe al analizar los gastos menores de la hermandad, que normalmente reflejan la adquisición de nuevas huchas con cierta periodicidad ${ }^{25}$. A diferencia de la anterior, la cofradía sacramental de San Andrés solo tenía un cepo en su capilla y otro en la casa del hermano mayor, por lo que como es lógico el volumen de ingresos a través de este medio entre una y otra era notablemente diferente. De hecho la suma de haberes procedentes de demandas y cepos constituía un $76 \%$ del total de ingresos para la

${ }^{21}$ GÓMEZ GARCÍA, Mª C., y MARTÍN VERGARA, J. M., "Bases económicas de las hermandades y cofradías en la Málaga moderna. Siglos XVI-XVIII", en ARANDA DONCEL, J. (coord.), Actas del III Congreso Nacional de cofradias de Semana Santa. Tomo I. Historia, Córdoba 1997, p. 661.

${ }^{22}$ Entre numerosos ejemplos A.G.O.C., Cofradías. Cofradía de Nuestra Señora de los Remedios. Licencia para pedir limosna, 1773-1787.

${ }^{23}$ A.G.O.C., Cofradias, 6568/03. 1757-1796. Cuentas de 1758.

${ }^{24}$ A.P.S.A.A., Libro de cabildos de la hermandad de Ánimas. 1700-1853. Memoria de los cepos que se han repartido (1758-1778). Fol. 123 r.-151 r.

${ }^{25}$ A.G.O.C., Cofradias, 6535/01. 1679-1776. Cuentas de 1758. 
cofradía de Ánimas en 1758 frente al 7,5\% de la cofradía sacramental unos años antes. Para la de San José, únicamente constituía un 4\% en 1764. El gran problema de estas partidas era la propia imprevisión a la hora de hacer unos cálculos para la organización económica, pues al depender de la voluntad de cofrades y devotos, el volumen de ingresos que procedía de las demandas callejeras era muy fluctuante de unas anualidades para otras.

Mucho más importante para las cofradías que las disfrutaban eran las rentas derivadas de sus bienes inmuebles y de capital. Entre los primeros las casas eran el capítulo más destacado. Así, la renta derivada del arrendamiento de estas propiedades generaba pingües beneficios económicos a sus cofradías. Una fuente que nos facilita el análisis de las posesiones inmuebles de las hermandades y cofradías cordobesas a mediados del siglo XVIII lo constituye el catastro de Ensenada. 45 de las 52 corporaciones que aparecen catastradas, es decir, menos de un tercio del total de agrupaciones que existían en la ciudad en estos momentos, eran propietarias de 196 casas por las que obtenían rentas adicionales a sus limosnas, con importantes diferencias entre las mismas. Así, la sacramental de San Lorenzo con veinte $\operatorname{casas}^{26}$ o la de la Virgen de la Consolación con algo más de catorce ${ }^{27}$, despuntaban frente a la media, que se situaba entre una y tres inmuebles arrendados por cofradía. Por los fines y la relevancia de las cofradías sacramentales, estas eran casi siempre las que más posesiones de este tipo tenían en comparación con el resto. En San Andrés la cofradía del Santísimo Sacramento llegó a acumular cinco viviendas ${ }^{28}$, mientras que la de las Nieves ${ }^{29}$, tan solo contaba con dos.

A la larga, disponer de casas no siempre era beneficioso para los intereses de las cofradías propietarias. En primer lugar, la mayoría de ellas eran fruto de donaciones testamentarias y venían fuertemente cargadas con sufragios y obligaciones cultuales en honor de los donantes, con la idea de que de las rentas de la vivienda que se cedía sirviesen para costear dichas cargas. En segundo lugar, dada la poca calidad de la mayoría de las viviendas del momento, eran necesarias continuas obras y reformas en las mismas para garantizar que estuviesen en un estado aceptable para ser arrendadas. Esto causaba gastos extras a las cofradías y en muchos casos el dinero que se obtenía de las viviendas no cubría el montante necesario para estas reparaciones y las cargas impuestas. De esta manera se daba lugar a incumplimientos en las obligaciones y a situaciones de asfixia económica como la que vivía la cofradía sacramental

\footnotetext{
${ }^{26} \mathrm{~A}$ (rchivo) $\mathrm{H}$ (istórico) $\mathrm{P}($ rovincial) (de) $\mathrm{CO}$ (rdoba), C(atastro) (de) E(nsenada), $\mathrm{CO}$ (rdoba). 1752. Vol. 329. Fol. 113 v.-133 r.

${ }^{27}$ A.H.P.CO., C.E., CO. 1752. Vol. 329. Fol. 237 v.-249 r.

${ }^{28}$ A.H.P.CO., C.E., CO. 1752 . Vol. 328. Fol. 151 r.-159 r.

${ }^{29}$ Ibidem, fol. 233 r.-335 v.
} 
de San Andrés a mediados de siglo. De hecho, tan solo dos de las más de once diferentes cargas que tenía la hermandad aparecen cumplidas en las cuentas de $1752^{30}$.

En otro orden de cosas, el frecuente cambio de arrendadores exigía que el hermano mayor tuviese que estar negociando continuamente para obtener rentabilidad de estas posesiones, aunque con carácter general a lo largo de la centuria se observa un claro proceso de inflación. Así, si por las casas de la calle Almonas, las más rentables para la cofradía de San Andrés, se cobraban de renta 22 ducados anuales en $1700^{31}$, en el año 1775 la hermandad percibía 36 ducados $^{32}$, un $63 \%$ más. Este incremento se detecta en el resto de sus viviendas. Aun así, a pesar de los precios pactados, en la citada cofradía se observan importantes atrasos de pagos de los inquilinos que dificultaban aún más la gestión económica. Volviendo a la cofradía sacramental de la parroquia de San Andrés, en 1752 un 40\% de las rentas que le correspondían por los arrendadores de sus viviendas no fueron pagadas a tiempo, lo que representó un total de 1.375 reales $^{33}$. A pesar de las desventajas, cuando las cofradías tenían suficientes recursos solían optar por hacerse con un bien de estas características que le proporcionase unas rentas fijas sobre las que poder organizarse ${ }^{34}$.

Algunas hermandades aparecen igualmente como propietarias de tierras, en concreto 16 de las 52 cofradías catastradas, siendo una de ellas la sacramental de San Andrés, que poseía un haza en el término de Casa Blanca, cerca de la ciudad. En general las propiedades rurales daban beneficios mucho menores que las viviendas pero no ocasionaban los gastos de las primeras en mantenimiento. Inevitables eran, sin embargo, los atrasos de los arrendadores. Normalmente los arrendamientos se abonaban para fechas señaladas del calendario como San Juan o la Navidad, y podía fraccionarse el pago de las rentas. La labor desamortizadora del gobierno de Godoy también se refleja en las cofradías estudiadas, como en el caso de la hermandad del Dulce Nombre de Jesús, del cenobio dominico de San Pablo, que en 1800 perdió un haza de olivos, de 3 fanegas y 4 celemines, enajenada y vendida por orden real ${ }^{35}$.

El otro gran pilar de la hacienda de las cofradías lo constituían los bienes de capital, fundamentalmente los censos. Estos préstamos generaban a las

\footnotetext{
${ }^{30}$ A.G.O.C., Cofradias, 6529/01. Cuentas de 1752.

${ }^{31}$ A.G.O.C., Cofradias, 6528/01, Inventario de los títulos y cuentas de la cofradía del Santísimo Sacramento, 1642-1715. Cuentas de 1700.

32 A.G.O.C., Cofradias, 6529/01. 1715-1775. Cuentas de 1775.

${ }^{33}$ Ibidem. Cuentas de 1752.

${ }^{34}$ GÓMEZ GARCÍA, M ${ }^{\mathrm{a}}$ C., y MARTÍN VERGARA, M., o.c. p. 662.

${ }^{35}$ A.P.S.A.A., Libro de la cofradía del Dulce Nombre de Jesús. Real convento de San Pablo, orden de predicadores. Posesiones propias de esta cofradía.
} 
cofradías unas rentas seguras pero menores que los bienes inmuebles, pues podían ser redimidos en un momento determinado por los pagadores. El estudio profundo de los censos nos refleja en primer lugar la acción de las pragmáticas reales de comienzos del siglo XVIII en la que se reduce el cobro de réditos a un $3 \%$, cifra que se mantiene durante el resto de la centuria ${ }^{36}$. De igual manera era frecuente, tanto en general como en los casos particulares, que estas corporaciones contrajesen préstamos con otros individuos o instituciones eclesiásticas, lo que nos dibuja un interesante flujo de crédito y recursos de unas corporaciones a otras pero siempre dentro de la propia Iglesia. En el caso de la sacramental, recibía dinero de los beneficiados de San Andrés y del convento de agustinas de la Encarnación Agustina, mientras que pagaba al hospital de Peregrinos y al convento de dominicas de Santa María de Gracia. Al igual que ocurría en el caso de las viviendas, los censos también estaban cargados con fiestas y otras obligaciones y observan atrasos importantes de pagos.

Dada la posibilidad de redimirse que tenían estos bienes de capital, a lo largo de la centuria se observan interesantes fluctuaciones y redenciones de censos tanto a favor como en contra de estas hermandades. Así, no es raro que de unas cuentas a otras varíen los censos. Sin embargo, a diferencia de otras instituciones y las personas físicas, una vez que el principal del censo a favor de la cofradía era redimido no pasaba a estar a disposición de la misma, sino que tenía que ser depositado en el palacio episcopal como dictaban las sinodales ${ }^{37}$, de manera que la mayor parte de las hermandades solía invertir este dinero en la imposición de otro censo a su favor o en adquisiciones de otros bienes inmuebles. La Iglesia impedía de esta manera que se pudiese despilfarrar un montante destinado a la inversión en pro de la institución, y su aplicación era inmediata, tal y como se observa cuando la cofradía de Ánimas intenta depositar la principal de 150 ducados de un censo redimido en su arca en 1702, pues tres meses después estaba de nuevo impuesto sobre unas casas en la calle Mucho Trigo ${ }^{38}$.

Finalmente, otros ingresos de las cofradías eran los recibidos de las donaciones que podían ser llevadas a cabo por destacados personajes en el seno de la hermandad, como los hermanos mayores, con el consiguiente reconocimiento que reportaba, como por devotos que podían contribuir en dinero o en especie.

${ }^{36}$ Esto se puede comprobar en censos de la cofradía sacramental, mientras que en 1700 los réditos son del 5\%, a partir de las siguientes cuentas analizadas (1720), ya ha bajado al 3\%.

37 Constituciones sinodales del obispado de Córdoba. 1662. Libro I. Título XIII. Capítulo II. 6, en NUÑEZ BELTRÁN, M. A. (coord.), SYNODICUM BAETICUM III. Constituciones sinodales y conciliares de las diócesis de Cádiz, Ceuta y Córdoba, Sevilla 2017, p. 520.

38 A.P.S.A.A., Libro de cabildos de la hermandad de Ánimas. 1700-1853. Cabildos de los días 24 de junio y 8 de septiembre de 1702 . Fol. 5 v.-7r. 
Dentro de este segundo caso encontramos desde bienes muebles para el culto, como custodias, palios, ropa para los titulares o cera hasta donaciones de otra índole como los beneficios de la siega de un campo de trigo del cortijo de Jaboncillo a la cofradía de Ánimas de San Andrés ${ }^{39}$ o incluso una marrana que donó Bartolomé Chillón a la cofradía sacramental del Campo de la Verdad ${ }^{40}$. Igualmente, en las cofradías del Campo de la Verdad era bastante frecuente el alquiler para sufragar sus gastos tanto de cera, de túnicas para realizar estación de penitencia en Semana Santa, de cajas de entierro y paños a otras cofradías de la ciudad, así como la celebración de rifas y sorteos ${ }^{41}$. La localización geográfica también influye en los ingresos de las cofradías, y así, en el barrio de San Nicolás de la Axerquía, pegado al río, encontramos cofradías como la del Huerto y Nuestra Señora de Loreto que arrendaba unos barcos ${ }^{42}$ y otras como la de las Ánimas que disponía de unas tinajas en la ribera del mismo ${ }^{43}$.

Los montantes totales de ingresos de las cofradías de San Andrés nos reflejan datos desiguales, pero en términos generales en orden descendente las hermandades de las que más volumen de dinero disponían para hacer sus gastos eran la sacramental, la de Ánimas, la de las Nieves y la de San José. Al no conservar datos de la cofradía de los Ángeles no podemos acercarnos a su realidad. A pesar de esto, no siempre las cofradías con más beneficios anuales eran las que se encontraban más saneadas económicamente.

\section{GASTOS}

En lo relativo a los gastos, el estudio de los mismos nos remite directamente a los fines y funciones de estas corporaciones. Sin lugar a duda el principal dispendio que en teoría debería tener cada cofradía era sufragar los cultos anuales. El coste de fiestas en honor a los titulares, con toda la solemnidad posible y asistencia de organistas, sochantres, un gran número de presbíteros o los costos de cera y aceite nos refleja la importancia de estos actos cultuales dentro de la realidad de la teatralidad barroca y la importancia de la celebración eucarística como centro principal de reunión de la comunidad. Sobre estos gastos tenemos una información muy elocuente contenida en el censo de cofradías de 1773, en las que reflejan el número de fiestas y los gastos de las mismas por cada corporación ${ }^{44}$. En este sentido, se observan las diferencias tan acusadas

\footnotetext{
${ }^{39}$ A.G.O.C., Cofradias, 6535/01. 1679-1776. Cuentas de 1728.

${ }^{40}$ A.G.O.C., Cofradias, 6568/03, 1757-1796. Cuentas de 1757.

${ }^{41}$ Ibid.

${ }^{42}$ A.H.P.CO., C.E. CO. 1752. Hac. Ecl. Vol. 329, fol. 330 v.-331 r.

${ }^{43}$ A.G.O.C., Cofradias, 6539/01. 1637-1840. Cuentas de 1702.

${ }^{44}$ Archivo Histórico Nacional, Consejos, 7091, expediente 9. 1773.
} 
en recursos y funciones que desarrollaba cada hermandad en la ciudad, lo que nos relaciona directamente con la composición social de sus miembros y la devoción y el número de hermanos con que contaba cada una. Así, es la de Jesús Nazareno la que encabeza la lista con unos gastos anuales de 11.000 reales por los costos de diecinueve fiestas más la salida procesional de la madrugada del Viernes Santo, la más esplendorosa de todas con cinco pasos, gastos que no podían sufragarse sin la generosa aportación de los nobles que conformaban la cofradía. En contraposición, la también aristocrática hermandad de la Caridad no presenta datos sobre sus libramientos, ya que sus rentas las destinaba a la curación de enfermos en el hospital. Las primeras posiciones las ocupan fundamentalmente hermandades penitenciales, sin duda por los gastos de las procesiones, y algunas sacramentales además de la del Rosario de San Pablo, la principal de cuantas hermandades rosarianas existían en la ciudad. Por el contrario, las que menos gastaban en cultos solían ser hermandades marianas y del rosario, junto con hermandades de ánimas y sacramentales de barrios más pobres.

Las cofradías del templo parroquial de San Andrés presentan acusados contrastes. La hermandad sacramental aplicaría 1.082 reales anuales a la celebración de 9 fiestas a lo largo del año. El doble que la que le sigue en inversión festiva, la de los Ángeles, dedicó 600 reales en otras 9 fiestas y la procesión acostumbrada. La cofradía de las Ánimas con 3 celebraciones y un costo de 500 reales, ocupa el tercer lugar. Mientras que San José, que pagaba 442 reales por el duodenario, y la Virgen de las Nieves y Santo Domingo, con 160 reales repartidos en 3 fiestas, cierran el listado ${ }^{45}$. Estas pinceladas nos aproximan al nivel de gasto real de cada cofradía en sus cultos durante la centuria. La del Santísimo y San Roque era la que más obligaciones tenía, tanto de las fiestas propias de la hermandad como de las cargas, que muchas veces buscaban también un engrandecimiento de los cultos de la cofradía como el acompañamiento de ministriles cuando saliese el Sacramento en viático para cuyo costo dejó Manuela de Cabreros las casas de la calle Humosa ${ }^{46}$. Sin embargo, la situación apretada de la hermandad hacía que la mayor parte de las mismas no se cumpliese hasta que se moderaron en la segunda mitad de la centuria. La fiesta principal de la cofradía de Ánimas era las honras solemnes de noviembre, mientras que la de las Nieves la fiesta en honor de la titular en agosto.

También podemos aquí incluir otros gastos cultuales como las diferentes misas que la hermandad de Ánimas realizaba por las almas del Purgatorio. El porcentaje sobre el total de los gastos de estas hermandades era muy diferentes

\footnotetext{
${ }^{45}$ Ibid.

${ }^{46}$ A.G.O.C., Cofradias, 6529/01. 1715-1775. Cuentas de 1752.
} 
de una a otra, aunque en general no superaba el $20 \%$, salvo en el caso de la cofradía de San José, cuyo único acto era la celebración del duodenario, en donde los gastos del mismo ascendían a un $70 \%$ del presupuesto total. A pesar de esto, sabemos que la falta de cumplimiento de la mayoría de estas obligaciones cultuales en el caso de la cofradía sacramental por todas las deudas a las que atender supuso que solo un $4 \%$ del dinero gastado fuese a sufragar dichas celebraciones en $1752^{47}$. Por el contrario, la cofradía de Ánimas en torno a esa fecha aplicaba un $44 \%$ del total de gastos a las honras y las diferentes misas dominicales y por las ánimas que se celebraban a su costa. En muchas de estas partidas se especificaba de manera detallada en qué se consumían los montantes totales. Por lo general, los derechos parroquiales o los sermones para los predicadores eran los principales gastos en las funciones religiosas, aunque también se incluían aspectos como el uso de juncia y otras hierbas aromáticas para perfumar el suelo de la calle, adorno de la iglesia, fuegos artificiales, traslado de los predicadores, pago a acólitos o colación y agasajos varios que se daban a los oficiantes y allegados. De ahí que algunas cofradías como la de las Nieves no celebrasen con tal solemnidad la fiesta anualmente $^{48}$. Gastos que nos dan una idea del esplendor que buscaban las hermandades en sus fiestas principales no solo como mayor demostración de devoción y culto a Dios, sino también como un reflejo del poder y relevancia de las mismas. Todo ello sin olvidar la rivalidad entre las diferentes cofradías por organizar los mejores, más solemnes y ricos ciclos cultuales.

Cuando a los cultos internos había que sumar salidas procesionales, que por las rentas no se podían celebrar todos los años, los gastos se disparaban por el gran número de diligencias que había que atender. Esto se demuestra en el caso de la cofradía sacramental del Campo de la Verdad. Así, si eran 60 reales los que gastaba anualmente en fiestas al Santísimo Sacramento y la Virgen del Rayo, los años que se celebraba la procesión, únicamente en tener todo a punto para la misma se invertían entre 800 y 1.000 reales $^{49}$. De aquí se explica la imposibilidad de poder salir todos los años para cofradías modestas como las del Campo de la Verdad, realidad que ocurría en casi todas las corporaciones cordobesas.

Junto a los gastos de culto, tanto interno como externo, otros capítulos frecuentes en el "debe" de la contabilidad de las hermandades eran los sufragios por los hermanos difuntos, que de media solían ocasionar unos 44 reales por fallecimiento en las cofradías de la collación estudiada o unas honras solemnes

\footnotetext{
${ }^{47}$ ANEXO. TABLA I.

${ }^{48}$ A.G.O.C., Cofradias, 6532/01. 1644-1776. Cuentas de 1749.

${ }^{49}$ A.G.O.C., Cofradias, 6568/03. 1757-1796. Cuentas de 1758.
} 
como las que organizaba la sacramental cuando disponía de recursos suficientes. A pesar de la imprevisibilidad del dinero necesario para afrontar estos gastos, nunca se prescindía de los sufragios por muy apurada que fuese la situación, ya que era uno de los principales motivos por los que los hermanos se inscribían en estas corporaciones. Aun así, no solían representar más del 10\% del total de los gastos a realizar por la hermandad. También hay que señalar entre las partidas de data los pagos de censos cargados sobre la cofradía y los gastos de reparaciones de aquellas hermandades que poseían casas. Este montante podía llegar a ser bastante alto en función del estado de las viviendas y de la necesidad de tener las mismas adecentadas para sacar rentabilidad a los bienes inmuebles. Se documentan igualmente casos de gastos en pleitos y colaciones a los hermanos, prácticas muy perseguidas por los obispos cordobeses tal y como se reflejan en las aprobaciones de cuentas de la cofradía sacramental del Campo de la Verdad de manera reiterada. De hecho, estas comidas eran duramente criticadas por los círculos ilustrados al señalar a las cofradías como ámbitos donde las comilonas y otras malas prácticas tenían un protagonismo destacado ${ }^{50}$.

La cera y el aceite eran productos que habitualmente compraba la cofradía para diferentes usos. La cera era fundamental para la iluminación y la celebración de las fiestas principales, además de para acompañamiento de entierros. El alto precio de la misma hace que sea una partida nada despreciable del conjunto de los gastos, en torno al $10 \%$ del total, que se disparaba cuando se organizaba el jubileo circular, que sumado a los gastos de adorno de la iglesia por el mismo llegaba a unos costos tal altos que documentamos solicitudes de cofradías como la del Rosario del Campo de la Verdad pidiendo que se excusase la celebración del mismo algunos años ${ }^{51}$. El aceite era igualmente importante para las cofradías sacramentales, que solían mantener de su costa encendida la lámpara del sagrario de la iglesia, así como la de ánimas que lo utilizaba para los faroles de las demandas nocturnas. Del estudio de los diferentes precios y partidas de productos como la cera o el aceite se podría reconstruir una evolución económica de los costos de los mismos, que en general tiende a subir.

Una partida que funcionaba como cajón de sastre era lo que en las cuentas aparece denominada como gastos menores. Entre ellos se recogían las pequeñas compras cotidianas formando una enorme amalgama de objetos, resultando

${ }^{50}$ ARIAS DE SAAVEDRA ALÍAS, I., y LÓPEZ-GUADALUPE MUÑOZ, M. L., "Debate político y control estatal de las cofradías españolas en el siglo XVIII", en ARIAS DE SAAVEDRA ALÍAS, I., y LÓPEZ-GUADALUPE MUÑOZ, M. L., La represión de la religiosidad popular. Crítica y acción contra las cofradías en la España del siglo XVIII, Granada 2002, pp. 230-234.

${ }^{51}$ A.G.O.C., Cofradias, 6568/06. 1753-1766. Cuentas de 1766. 
esta una información muy rica para el estudio de la cultura material. Campanitas, objetos sacros menores como manteles de altar, tela para elaborar vestidos, herramientas, zapatos para el muñidor, farolillos, varas, cepos, gastos del esterillado y limpieza de la capilla o de determinados procedimientos administrativos como solicitud de licencias o cartas de propiedad ante el escribano se encuentran en estos apartados tan heterogéneos que, por otro lado, podían llegar a suponer gastos importantes al conjunto total de la cofradía si en ellos se introducían adquisiciones de mayor calado como imágenes, retablos, lienzos de pintura u objetos de orfebrería para el culto ${ }^{52}$. Otros gastos serían el salario del muñidor, variable en función de la ocupación del mismo, el pago de impuestos como el subsidio o los costos de la propia elaboración de las cuentas en el obispado, que podrían ser mayores o menores en función de la longitud y de la falta de claridad de las mismas y donde se cobraban adminículos como el papel, los derechos correspondientes además de los diferentes traslados y notificaciones necesarias. En las cofradías de San Andrés, rara vez se han detectado gastos destinados a la propia solidaridad de los hermanos canalizados por los cauces oficiales de la cofradía, siendo el ejemplo más destacado las limosnas para dar de comer a los presos pobres de la cárcel en la década de $1730^{53}$.

Todo esto daba lugar a alcances a favor o en contra de estas cofradías cuyas tendencias cambiarían por periodos de mayor florecimiento o decadencia que incluso podría acabar con la desaparición de la cofradía ${ }^{54}$. En general, tanto las partidas de gastos como de ingresos analizadas eran las propias de las diferentes cofradías y hermandades tanto de la capital cordobesa como de otras como Granada ${ }^{55}$, Málaga ${ }^{56}$ y en general el resto de Andalucía, con peculiaridades en función de la corporación en cuestión y su localización geográfica.

\section{CONCLUSIÓN: UNA GESTIÓN ECONÓMICA}

De todo este amplio recorrido por la vida económica de las cofradías se puede observar cómo subyace claramente la existencia de una gestión económica en el seno de estas corporaciones que es dirigida por el hermano mayor o el mayordomo. A él le compete decidir, con las pertinentes consultas al cabildo de hermanos, qué decisiones tomar para la mayor salud económica de la

${ }^{52} \mathrm{~A}$ un $40 \%$ de los gastos llegaban en la cofradía de las Nieves en 1749.

53 A.P.S.A.A., Libro de cabildos y cuentas de la cofradia del Santísimo Sacramento y Señor San Roque. 1605-1736. Cabildos del día 21 de septiembre de 1732, 25 de febrero de 1734 y 6 de marzo de 1735.

${ }^{54}$ ANEXO. TABLA II.

${ }^{55}$ LÓPEZ-GUADALUPE MUÑOZ, M. L., Las cofradias de la parroquia de Santa María Magdalena de Granada en los siglos XVII-XVIII, Granada 1992, pp. 227-241.

${ }^{56}$ GÓMEZ GARCÍA, M ${ }^{\mathrm{a}}$ C., y MARTÍN VERGARA, J. M., o.c., pp. 659-664. 
cofradía que repercutirá en la mejor consecución de sus fines cultuales y asistenciales. Así, para sufragar los gastos fijos anuales derivados de los mismos las hermandades contaban con ingresos estables y otros variables, cuyos balances eran empleados tanto para potenciar estos fines como para invertir en algunos bienes muebles e inmuebles que a la larga fuesen de utilidad a la cofradía. Incluso, se desarrollaran métodos de todo tipo para recolectar dinero que garantice la mayor decencia y esplendor de los cultos, como en el caso de las costosas salidas procesionales, lo que implicaba un equipo gestor activo que no solo pusiese fin a deudas, atrasos de pagos y malos aprovechamientos de los recursos disponibles, sino que hiciera lo posible por aumentar los mismos, con métodos varios, desde la organización de rifas hasta la búsqueda de un patrocinio nobiliario. De este modo, podemos señalar que las corporaciones no eran entes estáticos en lo económico, ni siquiera que tuviesen unos ingresos y gastos fijos e inmutables año tras año, sino que desarrollaban su propia dinámica de compraventas y gestión de sus bienes para obtener la máxima rentabilidad. Es recurrente en este sentido la búsqueda de la mayor "utilidad" para la cofradía, tal y como figura en los cabildos de hermanos ${ }^{57}$.

Esta gestión también implicaba priorizar algunos gastos sobre otros cuando los recursos eran limitados o saber cuándo los fastos debían ser más comedidos en función de la realidad económica del momento. En este sentido podemos ver la propia importancia que daban las gentes de aquella época a cada uno de los fines para los que se había constituido la cofradía, que en función de la naturaleza de la misma, podría variar ${ }^{58}$. Estas decisiones de relevancia aunque competían al hermano mayor solían ser consultadas al conjunto de los cofrades. En todo momento evitar que los alcances fuesen tan elevados como para que la institución corriese peligro. No podemos señalar que la economía tenga valor por sí en estas instituciones, sino que su importancia radica en la salvaguarda de la corporación y su necesidad para poder cumplir los objetivos de la misma. El objetivo no era en ningún momento atesorar dinero, antes bien, cuando la hermandad poseía suficientes recursos invertía bien en la compra de nuevas casas o en la imposición de censos que le permitirá obtener rentas más fijas o bien en un aumento notable del esplendor del culto o de los sufragios por los difuntos.

En definitiva, la vida económica de las hermandades y cofradías nos ilustra no solo sobre los mecanismos estrictos por los que estas instituciones conseguían

57 A.P.S.A.A., Libro de cabildos y cuentas de la cofradia del Santísimo Sacramento y Señor San Roque. 1605-1736. Cabildo del día 26 de febrero de 1702.

${ }^{58}$ Aunque las diferentes cofradías y hermandades tuvieran fines parecidos, cada uno tenía los suyos propios que reflejaban en sus estatutos. Así, mientras que para una hermandad rosariana era prioritario fomentar la devoción a la Virgen a través del rezo del rosario de manera frecuente por las calles o en la iglesia, para una penitencial buena parte de la gestión se orientaba para organizar la estación de penitencia pública de Semana Santa. 
y gastaban sus recursos, sino sobre todo, los fines últimos de cada una de las corporaciones y la importancia que los cofrades asignaban a los mismos. Acercarse a la misma resulta por tanto vital para conocer buena parte de la vida de la cofradía, pues en la consecución y gastos de estos recursos se fundaban buena parte de los conflictos y pulsiones existentes en la corporación, su mantenimiento o su desaparición, además de darnos claves muy importantes estas instituciones que conjugaban religión, poder y sociedad, imprescindibles para entender la vida cotidiana en los núcleos urbanos de la Modernidad.

\section{ANEXO}

Por los límites de extensión, las tablas elaboradas se centran en la vida económica de la hermandad sacramental de la parroquia de San Andrés Apóstol durante el siglo XVIII.

\section{TABLA I: CUENTAS HERMANDAD SACRAMENTAL DE SAN ANDRÉS 1752 (1749-1752)}

\begin{tabular}{|l|c|}
\hline CARGO & $995 \mathrm{r}$. \\
\hline Deudas de la cuenta pasada & $38 \mathrm{r}$. \\
\hline Censo contra los beneficiados de la parroquia (6,6 r./año) & $0 \mathrm{r}$. \\
\hline Censo en Fernán Núñez (redimido) & $192,5 \mathrm{r}$. \\
\hline Censo contra el convento de la Encarnación Agustina (55 r./año) & $751,7 \mathrm{r}$. \\
\hline Rentas casas c/ Gragea (225,5 r./año) & $1.100 \mathrm{r}$. \\
\hline Rentas casas grandes c/ Almonas (330 r./año) & $249,3 \mathrm{r}$. \\
\hline Rentas casas c/ Queso (precios distintos por diferentes arrendadores) & $66,3 \mathrm{r}$. \\
\hline Rentas solar c/ Cidros (15 r. y luego 22 r./año) & $476,65 \mathrm{r}$. \\
\hline Rentas casas c/Humosa (143 r./año) & $880 \mathrm{r}$. \\
\hline Rentas casas pequeñas c/Almonas (264 r./año) & $153,3 \mathrm{r}$. \\
\hline Rentas haza de tierra en Casa Blanca (46 r./año) & $0 \mathrm{r}$. \\
\hline Censo en Bujalance (redimido) & $460 \mathrm{r}$. \\
\hline Demandas días de fiesta & $572 \mathrm{r}$. \\
\hline Mesa Jueves Santo & $0 \mathrm{r}$. \\
\hline Mandas testamentarias & $0 \mathrm{r}$. \\
\hline Limosna de cepos & $\mathbf{5 9 3 5 , 2}$ r. \\
\hline TOTAL & $594 \mathrm{r}$. \\
\hline DATA & $273,5 \mathrm{r}$. \\
\hline Alcance de la cuenta pasada & \multicolumn{2}{|l}{} \\
\hline Fiestas mensuales y misas rezadas por cargas &
\end{tabular}




\begin{tabular}{|l|c|}
\hline Aténtico día de los difuntos (no se ha cumplido) & $0 \mathrm{r}$. \\
\hline Gasto de cera & $496,5 \mathrm{r}$. \\
\hline Misas pro anima (44 r./hno.) & $132 \mathrm{r}$. \\
\hline Gasto procesión de impedidos (no se ha cumplido) & $0 \mathrm{r}$. \\
\hline Gasto ministriles (no se ha cumplido) & $0 \mathrm{r}$. \\
\hline Censo a favor del hospital de Peregrinos (44 r./año) & $132 \mathrm{r}$. \\
\hline Censo a favor del convento de Santa María de Gracia $(8$ r./año) & $32 \mathrm{r}$. \\
\hline Censo a favor de la obra pía de Miguel de Haro y redención a la mitad & $1.399,9 \mathrm{r}$. \\
\hline Gasto aceite & $190 \mathrm{r}$. \\
\hline Salario muñidor (89 r./año) & $271 \mathrm{r}$. \\
\hline Gastos menores & $357 \mathrm{r}$. \\
\hline Gastos de obras & $385 \mathrm{r}$. \\
\hline Débitos de pagos & $1.924,3 \mathrm{r}$. \\
\hline Deudas perdidas & $343,5 \mathrm{r}$. \\
\hline TOTAL & $\mathbf{6 . 5 3 0 , 7 ~ r . ~}$ \\
\hline ALCANCE & $\mathbf{- 5 9 5 , 5 ~ r . ~}$ \\
\hline
\end{tabular}

Fuente: Elaboración propia a partir de la documentación consultada.

\section{GRÁFICO I. CARGO DE LA HERMANDAD SACRAMENTAL 1752.}

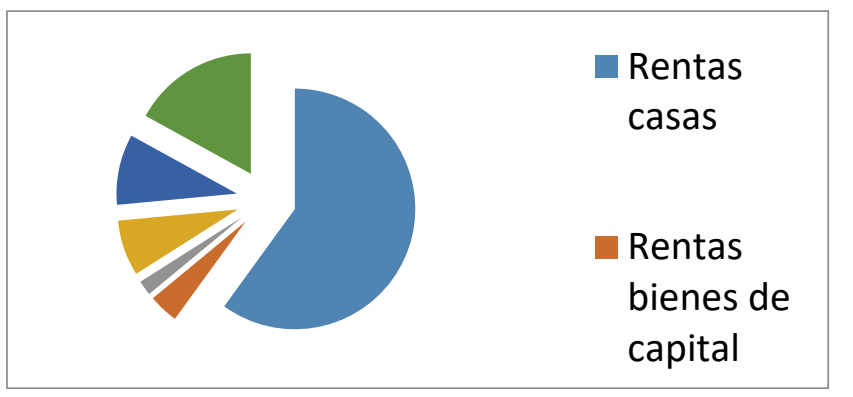

Gris: Rentas de tierras.

Amarillo: Demandas.

Azul oscuro: Cuotas de hermanos.

Verde: Deudas.

\begin{tabular}{|l|l|l|}
\hline Deudas & 995 r. & $17 \%$ \\
\hline Rentas (censos + casas + tierras) & $3.907,75$ r. & $66 \%(4+60+2)$ \\
\hline Limosnas (demandas + hermanos) & 1.032 r. & $17 \%(7.5+9.5)$ \\
\hline TOTAL & $5.935,2$ r. & $100 \%$ \\
\hline
\end{tabular}

Fuente: Elaboración propia a partir de la documentación consultada. 


\section{GRÁFICO II. DATA DE LA HERMANDAD SACRAMENTAL 1752.}

\begin{tabular}{|l|}
\hline \\
Alcance \\
anterior \\
Fiestas \\
religiosas \\
Misas pro \\
anima \\
Pago al \\
muñidor \\
Censos contra \\
la cofradía
\end{tabular}

\begin{tabular}{|l|l|l|}
\hline Alcance cuenta anterior & 594 r. & $9 \%$ \\
\hline Fiestas de la cofradía & 273,5 r. & $4 \%$ \\
\hline Misas pro anima & 132 r. & $2 \%$ \\
\hline Otros actos cultuales & 0 r. & $0 \%$ \\
\hline Censos contra la cofradía & 1.564 r. & $24 \%$ \\
\hline Aceite & 190 r. & $3 \%$ \\
\hline Cera & 496,5 r. & $7,5 \%$ \\
\hline Gastos menores & 357 r. & $5,5 \%$ \\
\hline Obras & 385 r. & $6 \%$ \\
\hline Subsidio & 0 r. & $0 \%$ \\
\hline Débitos de pagos & $1.924,3$ r. & $29,5 \%$ \\
\hline Deudas perdidas & 343,5 & $5,5 \%$ \\
\hline Muñidor & 271 r. & $4 \%$ \\
\hline Costes cuentas & 0 r. & $0 \%$ \\
\hline TOTAL & 6530,7 r. & $100 \%$ \\
\hline
\end{tabular}

Fuente: Elaboración propia a partir de la documentación consultada.

TABLA II: CARGOS, DATAS Y ALCANCES DE LA HERMANDAD SACRAMENTAL DURANTE EL SIGLO XVIII

\begin{tabular}{|l|l|l|l|}
\hline & \multicolumn{1}{|c|}{ Cargo } & \multicolumn{1}{c|}{ Data } & \multicolumn{1}{c|}{ Alcance } \\
\hline $1693-1700$ & $18.762,4 \mathrm{r}$. & $20.301 \mathrm{r}$. & $-1.538,73 \mathrm{r}$. \\
\hline 1701 & & & $+407,5 \mathrm{r}$. \\
\hline 1711 & & & $+1.953,1 \mathrm{r}$. \\
\hline
\end{tabular}




\begin{tabular}{|l|l|l|l|}
\hline 1715 & & & $+422,2$ r. \\
\hline 1720 & 19.775 r. & 20.048 r. & $-273,2$ r. \\
\hline 1734 & & & $+1.591,5$ r. \\
\hline 1738 & $8.120,9$ r. & $8.464,6$ r. & $-343,7$ r. \\
\hline 1743 & $11.189,9$ r. & $11.100,6$ r. & $+89,3$ r. \\
\hline 1744 & $5.012,1$ r. & $5.014,4$ r. & $-2,3$ r. \\
\hline 1749 & $9.828,1$ r. & $11.248,9$ r. & $-1.420,7$ r. \\
\hline 1752 & $5.935,2$ r. & $6.530,7$ r. & $-595,5$ r. \\
\hline 1760 & $15.696,35$ r. & $15.592,5$ & $+103,8$ r. \\
\hline 1763 & 7.689 r. & 7.267 r. & +422 r. \\
\hline 1771 & $18.860,45$ r. & $15.545,1$ r. & $+3.135,4$ r. \\
\hline 1775 & $12.194,7$ r. & $8.364,5$ r. & $+3.830,45$ r \\
\hline 1778 (año) & $2.000,2$ r. & $1.357,6$ r. & $+648,6$ r. \\
\hline $1780($ año) & $4.116,6$ r. & $11.307,3$ r. & $-7.190,6$ r. \\
\hline $1175-1780$ & $13.942,65$ r. & $21.345,3$ r. & $-7.402,6$ r. \\
\hline 1785 & $11.854,2$ r. & $16.074,8$ r. & $-4.220,65$ r. \\
\hline 1787 & $5.373,1$ r. & $8.782,75$ r. & $-3.409,7$ r. \\
\hline 1789 & $3.443,5$ r. & $5.246,8$ r. & $-1.803,6$ r. \\
\hline 1792 & $9.379,75$ r. & $9.483,5$ r. & $-103,8$ r. \\
\hline 1796 & $9.501,8$ r. & $5.788,6$ r. & $+3.732,1$ r. \\
\hline 1804 & $27.116,2$ r. & 17.539 r. & $+9.577,2$ r. \\
\hline
\end{tabular}

Fuente: Elaboración propia a partir de la documentación consultada.

\section{BIBLIOGRAFÍA}

- ALBERTONI, E., "Teoría de las élites y elitismo (apuntes para un análisis histórico y actual)", en Sistema: revista de ciencias sociales, 83 (1988) 43-56.

- ARANDA DONCEL, J., Cofradías y asistencia social en los barrios de San Juan y Todos los Santos (Trinidad), Córdoba 1990.

- ARIAS DE SAAVEDRA ALÍAS, I., y LÓPEZ-GUADALUPE MUÑOZ, M. L., "Debate político y control estatal de las cofradías españolas en el siglo XVIII", en ARIAS DE SAAVEDRA ALÍAS, I., y LÓPEZ-GUADALUPE MUÑOZ, M. L., La represión de la religiosidad popular. Crítica y acción contra las cofradias en la España del siglo XVIII, Granada 2002, pp. 229-246.

- ARIAS DE SAAVEDRA ALÍAS, I., y LÓPEZ-GUADALUPE MUÑOZ, M. L., "Cofradías y ciudad en la España del siglo XVIII", en Studia Historica. Historia Moderna, 19 (1998) 197-228. 
- GÓMEZ GARCÍA, Ma. C., y MARTÍN VERGARA, J. M., "Bases económicas de las hermandades y cofradías en la Málaga moderna. Siglos XVI-XVIII", en ARANDA DONCEL, J. (coord.), Actas del III Congreso Nacional de cofradias de Semana Santa. Tomo I. Historia, Córdoba 1997, pp. 659-664.

- GÓMEZ NAVARRO, S., "Cenobios femeninos de la España barroca: una mirada desde la Historia Social y del Género", en REVENGA DOMÍNGUEZ, P. (coord.), Arte barroco y vida cotidiana en el mundo hispánico. Entre lo sacro y lo profano, Córdoba 2017, pp. 279-300.

- LÓPEZ-GUADALUPE MUÑOZ, M. L., Las cofradias de la parroquia de Santa María Magdalena de Granada en los siglos XVII-XVIII, Granada 1992.

- MORENO VALERO, M., "Religiosidad popular en Córdoba en el silgo XVIII. Cofradías del Santo Rosario", en Boletín de la Real Academia de Córdoba, de Ciencias, Bellas Letras y Nobles Artes, 112 (1987) 95-111.

- MORGADO GARCÍA, A., "Cofradías y hermandades en el Cádiz de los siglos XVII y XVIII" en Actas de los VII Encuentros de Historia y Arqueologia. Gremios, hermandades y cofradias. Una aproximación cientifica al asociacionismo profesional y religioso en la Historia de Andalucia, San Fernando 1991, tomo I, pp. 43-66.

- NÚÑEZ BELTRÁN, M. A. (coord.), SYNODICUM BAETICUM III. Constituciones sinodales y conciliares de las diócesis de Cádiz, Ceuta y Córdoba. Sevilla 2017.

- RAMÍREZ DE ARELLANO Y GUTIÉRREZZ, T., Paseos por Córdoba o sean apuntes para su historia, León 1976.

- SANTOS GÓMEZ, M., "Una aproximación al asociacionismo religioso: la ciudad de Córdoba en el Antiguo Régimen", en MARINAS ARMEDÍA, A. (coord.), El mérito de la investigación, Córdoba 2019, pp. 38-41. 